Counsellia: Jurnal Bimbingan dan Konseling 8 (2), 59-70|November 2018

Copyright (O2017 Universitas PGRI Madiun

ISSN: 2088-3072 (Print) / 2477-5886 (Online)

Available online at: http://e-journal.unipma.ac.id/index.php/JBK

DOI: $10.25273 /$ counsellia.v8i2.2378

\title{
Meningkatkan planned happenstance skills dalam perspektif Al Qur'an Surah Al Balad
}

\author{
Muhammad Andri Setiawan ${ }^{1}$, M. Arli Rusandi ${ }^{2}$, Karyono Ibnu Ahmad ${ }^{3}$ \\ ${ }^{1}$ Fakultas Keguruan dan Ilmu Pendidikan, Universitas Lambung Mangkurat, Banjarmasin \\ andri.bk@ulm.ac.id \\ ${ }^{2}$ Fakultas Keguruan dan Ilmu Pendidikan, Universitas Lambung Mangkurat, Banjarmasin \\ arli.rusandi@ulm.ac.id \\ ${ }^{3}$ Fakultas Keguruan dan Ilmu Pendidikan, Universitas Lambung Mangkurat, Banjarmasin \\ karyonoia@gmail.com
}

\begin{abstract}
Abstrak
Makalah ini dimaksudkan untuk menjelaskan tentang meningkatkan planned happenstance skills dalam perspektif Al Qur'an surah Al Balad dari ayat 1 hingga ayat 20. Konsep planned happenstance skills percaya bahwa perilaku manusia merupakan produk dari pengalaman belajar yang tersedia dalam situasi terencana dan tidak terencana. Dalam ajaran Islam semua perilaku manusia tertumpu pada keyakinan bahwa segala sesuatu sudah merupakan rencana Allah, manusia hanya dituntut untuk mencoba dan kemudian mengembalikan hasil dari upaya tersebut kepada Allah. Dalam skema enam prinsip yang dapat diterapkan konselor untuk meningkatkan planned happenstance skills yang dikemukakan Krumboltz, surat Al Balad dapat menjadi alternatif alur yang unik dengan: (1) Menekankan mempercayai kehendak Allah, ayat 1-4; (2) Mengambil hikmah terhadap apapun yang telah terjadi, ayat 5-7; (3) Konseli didorong untuk bersikap fleksibel dalam menanggapi kondisi yang terjadi, ayat 8-10; (4) Konselor menerima umpan balik konseli, ayat 11-16; (5) Konseli dapat menafsirkan setiap hubungan komunikasi secara efektif, ayat 17-18; dan terakhir (6) Memastikan konseli menjalankan keseluruhan alur secara maksimal dan utuh, ayat 19-20.
\end{abstract}

Kata Kunci: konselor, planned happenstance skills, surah Al Balad,

\begin{abstract}
This paper is intended to express the increased planned happenstance skills based on Al Qur'an Surah Al Balad from verses 1 through 20. Planned happenstance skills believe in human behavior is the product of many learning experiences available by planned and unplanned situations. In the teachings of Islam everything is based on the belief that everything has been planned by Allah, man is required to be able to try and then return the results of such efforts to Allah. In the scheme of six counselor lines increasing the planned happenstance skill offered by Krumboltz, the Al Balad surah can be a unique alignment alternative with: (1) Emphasis to trust Allah, verses 1-4; (2) Taking wisdom on what has happened, verses 5-7; (3) The counselee is encouraged to be flexible in response to the circumstances, verses 8-10; (4) Counselors receive counselee feedback, verses 11-16; (5) The counselee can interpret every communication relation effectively, verses 17-18; and lastly (6) Ensure the counselee runs the overall flow as a whole and safely, verses 19-20.
\end{abstract}

Keywords: counselor, surah Al Balad, planned happenstance skills 


\section{PENDAHULUAN}

Menurut Laporan BPS pada tahun 2017, disebutkan bahwa dalam setahun terakhir, pengangguran bertambah 10 ribu orang. Dari 121,02 juta orang yang bekerja, sebesar 7,55 \% masuk kategori setengah menganggur dan 20,40\% pekerja paruh waktu.

Sempitnya lapangan pekerjaan pada kenyataannya tidak saja disebabkan oleh permasalahan ekonomi saja tetapi terdiri dari banyak faktor. Ananta (dalam Dewi Hartina S., 2009: 16) menyatakan bahwa angka pengangguran merupakan cerminan dari perubahan demografis dan bukan perubahan perekonomian.

Penelitian yang dilakukan oleh Andri Adi pada tahun 2016 terhadap penyebab tingginya pengangguran sarjana di Kecamatan Simeulue Barat Kabupaten Simeulue Provinsi NAD menemukan bahwa adanya ketidaksiapan lulusan sarjana untuk mandiri mengambil keputusan karier dalam menentukan pilihan tempat untuk bekerja karena ketidaksesuaian harapannya antara latar belakangan kesarjanaaan dengan pilihan pekerjaan yang diambil menjadi penyebab terjadinya pengangguran.

Ketidaksiapan mengambil sikap berkarier dalam bekerja, secara umum disebabkan oleh perilaku manusia dalam menentukan kariernya. Perilaku ini dapat diuraikan dalam The Happenstance Learning Theory (HLT) yang digagas Krumboltz pada tahun 2009 mengenai pengembangan karir. Krumboltz (2009:135) merangkum esensi HLT dengan menyatakan "HLT berpendapat bahwa perilaku manusia adalah produk dari banyak pengalaman belajar yang tersedia oleh situasi terencana dan tidak terencana dimana individu menemukan diri mereka sendiri. Hasil belajar meliputi keterampilan, minat, pengetahuan, kepercayaan, preferensi, kepekaan, emosi, dan tindakan di masa depan".

Dalam menjelaskan teorinya, Krumboltz (2009) memulai dengan menggambarkan sembilan faktor yang mempengaruhi perilaku individu, yaitu:

1. Bahwa genetika berperan dalam banyak variabel psikologis penting.

2. Pengalaman belajar yang dimiliki individu dapat memainkan peran penting.

3. Pengalaman belajar instrumental dimana individu mengamati perilaku mereka sendiri dan konsekuensinya dapat mempengaruhi perilaku mereka.

4. Mengaitkan pengalaman belajar, dimana individu mengamati perilaku orang lain, bisa berpengaruh.

5. Kondisi lingkungan dan kejadian dapat memainkan peran penting dalam mempengaruhi perilaku individu 
6. Dampak orang tua dan pengasuh juga dapat berdampak signifikan terhadap perilaku.

7. Kelompok sebaya telah ditemukan berperan dalam membentuk perilaku individu.

8. Jenis pengaturan pendidikan terstruktur yang dialami individu saat tumbuh dewasa dapat berdampak besar terhadap tingkah laku mereka, baik atau buruk.

9. Dunia yang tidak sempurna dimana kita tinggal memberikan kesempatan bagi beberapa orang dan bukan untuk orang lain.

Krumboltz dan rekan-rekannya telah mengembangkan teori tentang bagaimana individu membuat keputusan karir yang menekankan pentingnya perilaku (tindakan) dan kognisi (mengetahui atau berpikir) dan memanfaatkan kesempatan dalam membuat keputusan karir (Krumboltz, 2009).

Sehingga Mitchell et. al (1999) mengusulkan dan mengembangkan Planned Happenstance Theory sebagai alternatif untuk pergeseran yang cepat dalam dunia kerja dan menjelaskan "faktor kesempatan" dalam pengembangan karir individu. Mereka menggambarkan kejadian tak terduga sebagai peluang yang memiliki konsekuensi positif, meskipun peristiwa ini pada mulanya tidak disengaja atau tak terduga.
Selain planned happenstance skill/PHS dalam kaitannya memahami sebuah happenstance/kebetulan tidak hanya sebagai peristiwa kebetulan dan pengalaman, tetapi juga sebagai kemampuan individu untuk mencari peristiwa tersebut dan pengalaman yang dapat memaksimalkan belajar mereka (Krumboltz, et. al, 2013), individu juga harus mempunyai self efficacy dalam keputusan karir (career decision self efficacy/CDSE). Karena akan percuma planned happenstance skill/PHS tinggi tetapi individu tidak mempunyai keyakinan dirinya dalam hal keputusan karir terkait happenstance/kebetulan yang terjadi dalam hidupnya.

Dalam happenstance learning theory, lima keterampilan sangat membantu dalam menangani peluang karir. Keterampilan ini adalah rasa ingin tahu, ketekunan, fleksibilitas, optimisme, dan mengambil risiko (Mitchell et al., 1999), seperti yang dijelaskan di bawah ini:

1. Keingintahuan/Curiosity digunakan untuk mengeksplorasi peluang belajar baru dan menindaklanjuti pilihan yang dihasilkan dari kejadian kebetulan.

2. Kegigihan/Persistence dipelajari saat ada kemunduran dalam pengalaman seseorang. Misalnya, jika seorang konseli tidak ditawari 
pekerjaan tapi terus berusaha, dan akhirnya hasil wawancara kerja menghasilkan sebuah tawaran, konseli dapat belajar ketekunan.

3. Fleksibilitas/Flexibility dipelajari saat berhadapan dengan banyak peristiwa kebetulan. Individu sering fleksibel dalam mengubah sikap mereka saat menghadapi keadaan yang berbeda seperti atasan yang berbeda dalam wawancara kerja yang berbeda.

4. Optimis/Optimism adalah melihat peluang baru sebaik mungkin dan dapat dicapai.

5. Mengambil risiko/Risk taking terjadi saat ada kejadian baru yang tak terduga. Konseli mengetahui bahwa mengambil risiko (misalnya, saat wawancara untuk pekerjaan di mana konseli tidak merasa cukup berkualifikasi) dapat menghasilkan hasil yang positif. Hasilnya mungkin bukan tawaran pekerjaan yang diinginkan melainkan membukakan peluang pekerjaan lain.

Pada kenyataannya batasan yang diuraikan The Happenstance Learning Theory (HLT) dalam perspektif Islam, hanya sampai pada batasan ikhtiar, tidak sampai tawakal padahal dari tawakal atau berserah diri kepada Allah maka penyerahan akan hasil ikhtiar atau usaha akan terbentuk secara alami membentuk ketenangan batin. Abu Zakariya Sutrisno (2016) menyatakan jika mengimani Allah yang menentukan segala sesuatu maka sudah semestinya bertawakal kepada Allah. “...Dan hanya kepada Allah hendaknya engkau bertawakal, jika engkau benar-benar orang yang beriman" (QS. Al Maa'idah [5]: 23)

Tawakal hendaknya disertai dengan ikhtiar (usaha), maka tidak benar jika ada orang yang mengatakan bertawakal kemudian berpangku tangan dan meninggalkan ikhtiar. Pada hakikatnya orang yang seperti ini bukan orang yang bertawakal, tetapi seorang pemalas.
Allah
memerintahkan bertawakal dan menyatakan bahwa Allah tidak akan mengubah keadaan seseorang atau suatu kaum jika mereka tidak berusaha mengubahnya sendiri.

Sesungguhnya Allah tidak merobah keadaan sesuatu kaum sehingga mereka merobah keadaan yang ada pada diri mereka sendiri." (QS. Ar Ra'd [13]: 11).

Peningkatan kemampuan Planned Happenstance Skills perlu juga didorong dengan spirit ikhtiar dan tawakal secara berimbang. Konselor yang mempergunakan konsep HLT dapat mempertimbangkan keseluruhan surah Al Balad sebagai uraian alternatif meningkatkan Planned Happenstance Skills. 
Hal ini menjadi penting karena surah Al Balad berisi pelajaran bahwa manusia harus bersusah payah dan berjuang mengatasi kesulitan supaya dapat mempersembahkan sesuatu yang baik bagi masyarakat. Keberhasilan mempersembahkan kebaikan itu akan membuahkan kebahagiaan. Ketidaksediaan mengerjakan sesuatu yang bermanfaat bagi masyarakat akan membuahkan kesengsaraan (Kementerian Agama RI, 2010: 674).

\section{PEMBAHASAN}

Krumboltz

memperkenalkan The Happenstance Learning Theory untuk konselor karir memfasilitasi konseli mereka tentang pentingnya terlibat dalam berbagai kegiatan yang menarik juga bermanfaat, memastikan reaksi mereka, sisanya waspada terhadap peluang alternatif, dan keterampilan belajar untuk berhasil dalam setiap kegiatan baru. The Happenstance Learning Theory memperluas ide-ide dari teori-teori pengembangan karir tradisional dengan memasukkan peristiwa yang tidak direncanakan sebagai faktor penting dalam proses pengembangan karir (Kim, et. al, 2014).

Meskipun peluang masa depan sering dibuat tanpa kemauan seseorang, mereka dapat membuat dengan sengaja serta memanfaatkan lima komponen Planned Happenstance Skill/PHS (Mitchell, et. al 1999). Lima komponen
Planned Happenstance Skill/PHS digunakan untuk mengenali, menciptakan, dan menggunakan kejadian tak terduga sebagai peluang (Mitchell, et. al, 1999).

Keterampilan tersebut adalah rasa ingin tahu (menjelajahi kesempatan belajar baru), ketekunan (mengerahkan usaha meskipun mengalami kemunduran), fleksibilitas (mengubah sikap dan keadaan), optimisme (melihat peluang baru sebagai kemungkinan dan bisa dicapai), dan pengambilan risiko (mengambil tindakan dalam menghadapi hasil yang tidak pasti). Selanjutnya oleh Kim, et. al (2014b) lima komponen ini dikembangkan menjadi skala Planned Happenstance Career Inventory (PHCI) yang akan dipakai sebagai instrument dalam penelitian ini. Kelima keterampilan menyoroti kebutuhan untuk membantu konseli memanfaatkan peristiwa happenstance/kesempatan untuk memperluas potensi karir mereka. Selain itu juga dengan Planned Happenstance Skill/PHS dapat menuntun individu mengenal peluang dan berani mengambil resiko atas tindakannya. Konsisten dengan teori ini, Kim, et. al (2014a) juga menegaskan bahwa individu dengan planned happenstance skill tinggi akan meningkatkan kepuasan karir mereka.

S. Ahn, et.al (2015) dalam penelitiannya menemukan occupational identity status yang 
lebih tinggi (yaitu, moratorium dan achievement statuses) secara signifikan terkait dengan 5 komponen planned happenstance skill. Dengan kata lain individuindividu yang memiliki planned happenstance skill lebih cenderung untuk menunjukkan identity achievement statuses (status dimana remaja telah melalui krisis identitas dan telah membuat komitmen pada perasaan akan identitas diri yaitu peran atau nilai tertentu bahwa ia telah memilih) dan identity moratorium statuses (status di mana remaja saat ini dalam krisis, mengeksplorasi berbagai komitmen dan siap untuk membuat pilihan, namun belum membuat komitmen pada pilihan tersebut).

Sehingga Rhee, et. al (2015) melanjutkan penelitian untuk lebih meyakinkan terhadap pola identik dari enam vocational identities dan merekomendasikan perlunya meningkatkan Planned Happenstance Skill untuk pengembangan karir mahasiswa, namun keterampilan spesifik (indikator PHS) yang dibutuhkan mungkin berbeda tergantung pada vocational identity status mereka.

Beberapa prinsip yang bisa diterapkan konselor terkait upaya peningkatan Planned Happenstance Skill (Krumboltz, et. al, 2013; Krumboltz, 2015).

1. Konselor memahami bahwa hampir tidak mungkin memprediksi dunia yang kompleks ini, maka kesempatan benar-benar bisa dijadikan sebuah peluang. Konselor mungkin memberi contoh perubahan yang terus berlanjut di dunia, dan saat menyadari bahwa kejadian pada awalnya sangat menyedihkan, dia meyakinkan konseli bahwa mereka akan bekerja sama untuk menemukan peluang tersembunyi dalam peristiwa yang tidak direncanakan ini.

2. Konselor membantu konseli mereka melakukan tindakan konstruktif sekarang untuk mengeksplorasi dunia mereka.

3. Eksplorasi ini harus menghasilkan keterampilan, pengetahuan, dan kontak yang mungkin berguna dengan cara yang pada awalnya tidak dapat diprediksi.

4. Konselor harus mendapatkan umpan balik cepat dari konseli tentang hasil awal tindakan eksplorasi mereka.

5. Konselor harus menindak lanjuti setiap konseli untuk mendorong tindakan baru atau berkelanjutan untuk mengeksplorasi dunia konseli.

6. Konselor harus menyimpan semua komunikasi konseli sebagai bukti keefektifan pengalaman belajar alternatif. 
Pada Al Qur'an dalam surah Al Balad ayat 1-20 apabila kita simak sebagai berikut.

(1) Aku benar-benar bersumpah dengan kota ini (Mekah) (2) dan engkau (Muhammad) bertempat di kota Mekah ini (3) dan demi bapak dan anaknya (4) Sesungguhnya Kami telah menciptakan manusia berada dalam susah payah (5) Apakah manusia itu menyangka bahwa sekali-kali tiada seorangpun yang berkuasa atasnya (6) Dan mengatakan: "Aku telah menghabiskan harta yang banyak" (7) Apakah dia menyangka bahwa tiada seorangpun yang melihatnya (8) Bukankah Kami telah memberikan kepadanya dua buah mata (9) lidah dan dua buah bibir (10) Dan Kami telah menunjukkan kepadanya dua jalan (11) Tetapi dia tiada menempuh jalan yang mendaki lagi sukar (12) Tahukah engkau apakah jalan yang mendaki lagi sukar itu (13) (yaitu) melepaskan budak dari perbudakan (14) atau memberi makan pada hari kelaparan (15) (kepada) anak yatim yang ada hubungan kerabat (16) atau kepada orang miskin yang sangat fakir (17) Dan dia (tidak pula) termasuk orang-orang yang beriman dan saling berpesan untuk bersabar dan saling berpesan untuk berkasih sayang (18) Mereka (orang-orang yang beriman dan saling berpesan itu) adalah golongan kanan (19) Dan orang-orang yang kafir kepada ayatayat Kami, mereka itu adalah golongan kiri (20) Mereka berada dalam neraka yang ditutup rapat (QS. Al Balad [90]: 1-20).

Menurut

penafsiran

Kementerian Agama RI (2010: 668,
670, 673 dan 674) surah Al Balad mengandung sejumlah penjelasan, apabila disimpulkan adalah sebagai berikut.

1. Pada ayat ke 1 sampai ayat ke 4 disimpulkan bahwa Alah ingin menekankan pesan-Nya yang amat penting dengan bersumpah terlebih dahulu dengan orangorang dan tempat yang agung. Isi sumpah itu adalah bahwa manusia harus berjuang untuk bisa hidup dan menghidupkan kebenaran. Berdasarkan perjuangan itulah, Alah menilai manusia. Manusia seharusnya meninggalkan jasa, kecil atau besar.

2. Di ayat ke 5 sampai ayat ke 10 diungkapkan agar manusia tidak boleh sombong, karena pasti ada yang lebih hebat darinya. Yang terhebat itu hanyalah Alah. Manusia tidak boleh ria dalam berkorban, karena penghasilan yang didapatkannya untuk bisa berkorban itu diperolehnya melalui kemampuan yang diberikan Alah. Oleh karena itu, manusia perlu mensyukuri nikmat Alah yang tiada tara kepadanya, yaitu mata, lidah dan nafsu dengan menggunakannya untuk hal-hal yang diridhoi-Nya.

3. Ayat ke 11 sampai ayat ke 18 ditegaskan oleh Alah agar kaum Muslimin harus mampu menyelesaikan pekerjaanpekerjaan besar dan berat. Pekerjaan besar dan berat yang urgen bagi kemanusiaan itu 
misalnya, memerdekan budak, memberi makan orang lapar pada saat kelaparan, dan saling berwashilah untuk bersabar dan saling menyayangi. Mereka yang mampu melaksanakan pekerjaanpekerjaan besar itu digolongkan 'golongan kanan', yang imbalannnya adalah surga yang penuh nikmat.

4. Ayat ke 19 dan ayat ke 20 menguraikan bahwa mereka yang tidak mau bersusah payah dengan mengerjakan perbuatan-perbuatan baik yang sangat urgen bagi kemanusiaan akan dijebloskan Alah ke dalam neraka. Mereka itu, orang yang tidak mau bersusah payah mengerjakan perbuatan-perbuatan baik akan merugi dan bernasib malang di akhirat.

Keseluruhan surah Al Balad dapat menjadi alternatif meningkatkan Planned Happenstance Skills, tentu saja dengan melihat keterpaduan keduanya dilihat dari kesamaan alur, sebagaimana tertera pada tabel berikut.

Tabel 2.1 Internalisasi Sural Al Balad Meningkatkan Planned Happenstance

\begin{tabular}{|c|c|c|}
\hline Skema Krumboltz & $\begin{array}{l}\text { Ayat Surah } \\
\text { Al Balad }\end{array}$ & Internalisasi \\
\hline $\begin{array}{l}\text { Meyakinkan konseli terdapat } \\
\text { peluang pada setiap peristiwa }\end{array}$ & $1-4$ & $\begin{array}{l}\text { Menekankan } \\
\text { mempercayai kehendak } \\
\text { Allah }\end{array}$ \\
\hline $\begin{array}{lr}\text { Tindakan } & \text { konstruktif } \\
\text { mengeksplorasi dunia konseli }\end{array}$ & $5-7$ & $\begin{array}{l}\text { Mengambil hikmah } \\
\text { terhadap apapun yang } \\
\text { telah terjadi }\end{array}$ \\
\hline $\begin{array}{l}\text { Eksplorasi meliputi } \\
\text { keterampilan, pengetahuan, } \\
\text { dan kontak konseli }\end{array}$ & $8-10$ & $\begin{array}{l}\text { Bersikap fleksibel dalam } \\
\text { menanggapi berbagai } \\
\text { kondisi }\end{array}$ \\
\hline Melakukan umpan balik & $11-16$ & $\begin{array}{lll}\text { Umpan } & \text { balik } & \text { dari } \\
\text { belenggu pikiran } & \text { dan } \\
\text { ketulusan diri } & \end{array}$ \\
\hline Tindak lanjut & $17-18$ & $\begin{array}{lr}\text { Menafsirkan } & \text { setiap } \\
\text { hubungan } & \text { komunikasi } \\
\text { secara efektif } & \end{array}$ \\
\hline $\begin{array}{l}\text { Memastikan konseli mampu } \\
\text { menjalankan } \\
\text { alur }\end{array}$ & $19-20$ & Kesadaran diri \\
\hline
\end{tabular}

1. Peran konselor yang meyakinkan konseli terdapat yang peluang tersembunyi pada setiap peristiwa yang tidak direncanakan. Dalam perspektif ini maka peranan tawakal untuk berseserah diri kepada Allah Swt perlu ditanamkan. Konselor bersama 
konseli untuk usaha atau ikhtiar tersebut adalah bagian terpenting kehidupan karena sejatinya manusia sepanjang kehidupan akan senantiasa berjuang. Pada ayat ke 4 dari surah Al Balad menjadi bukti: "Sesungguhnya Kami telah menciptakan manusia berada dalam susah payah." Adapun ayat pertama hingga ayat ketiga refleksi dari perjuangan kehidupan di dunia dari negeri menjadi gambaran kehidupan duniawi hingga sebutan bapak dan anak akan pentingnya suatu hubungan/silaturrahmi untuk menciptakan suatu peluang. Pada kesempatan ini maka keingintahuan/curiosity adalah bukti pentingnya nilai kehidupan duniawi dengan dilandasi silaturrahmi.

2. Tindakan konstruktif mengeksplorasi dunia konseli, terkait pada cara konseli memahami dan memanfaatkan sesuatu yang ada dalam dirinya maupun yang berada pada lingkungannya. Al Qur'an pada surah Al Balad mengistilahkannya sebagai harta atau materi. Ayat ke 5 sampai ayat ke 7 menjadi dasar bagi konselor untuk menyadarkan konselor bahwa ada kekuatan besar penentu segala sehingga manusia perlu menyadari bahwa segala sesuatu di dunia ini berjalan bukan dengan sendirinya namun dirancang dalam bentuk ketentuan dan kekuasaan Allah
Swt. Eksplorasi yang dimaksud bagi konseli di sini sudah tentu menemukan hikmah dalam rentetan peristiwa yang membentuk kausalitas. Tujuan akhir adalah terbentuknya sikap kegigihan/persistence.

3. Eksplorasi yang dimaksud konselor membentuk keterampilan, pengetahuan, dan kontak. Prasyarat yang dimaksud hendaknya memiliki kondisional yang mendukung konseli itu sendiri, sehingga pada akhirnya konseli yang dimaksud akan menjadikan konseli fleksibel menghadapi kehidupan dunia. Pada ayat ke 8 sampai ayat ke 10 surah Al Balad dapat menjadi kriteria mendasarinya.

a. Pada ayat ke 8: “....dua buah mata" ilustrasi ini menjadi bukti bahwa sudah selayaknya pengetahuan yang dimiliki akan menjadi petunjuk konseli agar tidak tersesat. Semisalnya latar belakang pendidikan kesarjanaan ketika berhadapan dengan karier atau pekerjaan yang berbeda namun akan membentuk nuansa yang khas karena tidak ada sesuatu yang sia-sia.

b. Ayat ke 9: "lidah dan dua buah bibir"merefleksikan

keterampilan yang dimiliki baik yang lahir karena bakat secara alami ataupun terbentuk 
karena proses pendidikan atau pelatihan tertentu.

c. Di ayat ke 10:"...dua jalan." Memandang peluang yang diperoleh didukung ketegasan dalam menyusun rencana dan pilihan. Kemtangan berpikir perlu disadari secara utuh dan benar.

4. Umpan balik yang diterima konselor dari konseli merupakan hasil yang didapat konseli dari menjelaskan upaya yang telah dilakukan alur ketiga sebelumnya. Inspirasi dari surah Al Balad ayat ke 11 sampai ayat ke 16, yang apabila disimpulkan maka konselor perlu menekankan konseli untuk, sebagai berikut.

a. Memerdekakan diri dari belenggu pikiran sempit terhadap materi untuk mampu berbagi kepada mereka yang membutuhkan walaupun itu sebenarnya kecil atau pun sederhana, sehingga konseli menyadari ada orang yang lebih kurang atau lebih sulit situasinya dibandingkan konseli sendiri.

b. Menjalin komunikasi atau silaturrahmi dengan dilandasi rasa ketulusan dan keikhlasan bukan karena membutuhkan atau karena kepentingan. Komunikasi ini dibangun dalam rangka membangun kesadaran ketakwaan, sehingga optimisme terbentuk.
5. Pada alur selanjutnya adalah tindak lanjut yang melahirkan tindakan baru yang berkelanjutan. Tindakan yang dimaksud akan melahirkan sikap yang saling berpesan, menguatkan kesabaran dalam lingkup kasih sayang. Konselor perlu memastikan konseli bahwa ia telah melakuan hubungan baik dengan sesama sehingga mendapatkan manfaat besar dari komunikasi yang terjalin, sebagaimana disebut pada alur ke 6. Alur ke 5 ini merefleksikan ayat ke 17 dan ayat ke 18 surah Al Balad, sehingga konseli berani mengambil resiko.

6. Alur terakhir pada prinsipnya memastikan konseli mampu menjalankan keseluruhan alur yang dimaksud secara maksimal dan utuh. Secara apresiasi simbolik kita akan menyadari ini sebagaimana tertuang pada ayat ke 19 hingga ayat 20 surah $\mathrm{Al}$ Balad.

\section{SIMPULAN}

Pengembangan

planned happenstance skills tidak terlepas dari kesadaran akan adanya ikhtiar dan tawakal kepada Allah Swt. Namun apabila ikhtiar saja yang dilakukan tanpa melibatkan peranan akan kesadaran bahwa Allah Swt yang menentukan segalanya, maka kesadaran positif untuk menerima kenyataan hidup terasa sulit khususnya dalam membangun karir. Dalam Al Qur'an alur membangun 
planned happenstance skills sudah ada yakni dengan mengacu pada surah Al Balad.

Akan tetapi sudah tentu perlu dilakukan penelitian yang mendalam tentang wacana yang dikemukakan penelitian dalam mengembangkan planned happenstance skills ini.

\section{DAFTAR PUSTAKA}

Al Qur'an.

Adi, Andri. (2016). Analisis Penyebab Tingginya Pengangguran Sarjana di Kecamatan Simeulue Barat Kabupaten Simeulue. (Skripsi, Universitas Teuku Umar).

Ahn, S., et. al (2015). "Planned Happenstance Skills and Occupational Identity Status in High School Students". The Career Development Quarterly, 63(1): 31-43.

Badan Pusat Statistik. (2017). Keadaan Ketenagakerjaan Indonesia Agustus 2017. Tersedia:

https://www.bps.go.id/pressre lease/2017/11/06/1377/agustu s-2017--tingkatpengangguran-terbuka--tpt-sebesar-5-50-persen.html [22 Maret 2018].

Kementerian Agama RI. (2010). Al Qur'an dan Tafsirnya: Jilid X Juz 28-29-30. Jakarta: Penerbit Lentera Abadi.

Kim, B., et al (2014a). "A Moderated Mediation Model of Planned Happenstance Skills, Career Engagement, Career Decision Self-Efficacy, and Career Decision Certainty". The
Career Development

Quarterly, 62: 56-69.

Kim, B., et. al (2014b). "Construction and Initial Validation of the Planned Happenstance Career Inventory". The Career Development Quarterly, 62: 239-253.

Krumboltz, et. al (2013). "Applying the Happenstance Learning Theory to Involuntary Career Transitions". The Career Development Quarterly, 61(1): 15-26.

Krumboltz, J. D. (2009). "The Happenstance Learning Theory". Journal of Career Assessment, 17: 135-154.

Krumboltz, J. D. (2015). "Practical Career Counseling Applications of the Happenstance Learning Theory" dalam P. J. Hartung, M. L. Savickas, dan W. B. Walsh (Ed.), American Psychological Association Handbook of Career Intervention. Washington, DC: American Psychological Association. Hlm. 283-292.

Mitchell, et. al (1999). "Planned Happenstance: Constructing Unexpected Career Opportunities". Journal of Counseling \& Development, 77: 115-124.

Rhee, E., et. al (2015). "The Relationship among the Six Vocational Identity Statuses and Five Dimensions of Planned Happenstance Career Skills". Journal of Career Development, 43(4): 368-378.

S., Dewi Hartina. (2009). "Faktorfaktor yang Mempengaruhi 
Andri, Arli, Karyono; Meningkatkan planned happenstance skills dalam .... $\quad 70$

Pengangguran Terselubung di Perdesaan Jawa Tengah:

Analisis Data Sakernas 2007." Jurnal Kependudukan Indonesia, IV(1): 15-32.

Sutrisno, Abu Zakariya. (2016).

Tawakal dan Ikhtiar.

Tersedia:

https://ukhuwahislamiah.com

/tawakal-dan-ikhtiar/ [22

Maret 2018]. 